\title{
APPLICATION OF FRICTION STIR METHOD FOR WELDING OF MAGNESIUM ALLOYS AND OF THEIR STRUCTURE MODIFYING
}

\author{
A.L. MAJSTRENKO ${ }^{1}$, V.A. LUKASH ${ }^{1}$, S.D. ZABOLOTNY ${ }^{1}$ and R.V. STRASHKO ${ }^{2}$ \\ ${ }^{1}$ V.N. Bakul Institute for Superhard Materials, NASU \\ 2 Avtozavodskaya Str., Kiev, 04074, Ukraine.E-mail:3ab@ukr.net \\ ${ }^{2}$ E.O. Paton Electric Welding Institute, NASU \\ 11 Kazimir Malevich Str., 03680, Kiev, Ukraine. E-mail: office@paton.kiev.ua
}

\begin{abstract}
A technological process was developed for friction stir processing of surfaces of parts from magnesium and aluminum alloys for structure modification directed on formation of layer of fine-grain alloy structure (grain size 1.2-4.5 $\mu \mathrm{m}$ ) that is $16-63$ times less than the initial metal grain size $(75.8 \mu \mathrm{m})$. It is determined that the maximum temperature of alloy heating in zone of contact interaction of a tool with FS-processed layers of the samples from researched alloys has reached $340-380{ }^{\circ} \mathrm{C}$. Analysis of effect of kinetic parameters of the tool on change of microstructure of modified surface layers of the parts and welded joints was carried out. 18 Ref., 11 Figures, 3 Tables.
\end{abstract}

Ke y wo r d s: friction stir welding, heat generation at fruction stir process, plastic deformations, width of thermomechanical-affected zone, microstructure grain size

Regardless the fact that all the processes for joining structure metallic parts using electric arc, plasma, laser or electron beam and their combinations differ by separate process and economic advantages, but all of them have one common thing, i.e. presence of liquid phase in the joining zone, using which they are connected. This fundamental and important peculiarity of the process provides for a change of metal structure after its recrystallization, in particular, increase of grain size, phase transformations as well as formation of residual welding stresses, which have negative effect on welded joint strength. Therefore, during the whole history of metal fusion welding, the scientists from all over the world tried to develop the alternative methods of joining, in particular, solid-phase ones, which allow, at least partial, reduction of effect of mentioned phenomena.

Bevington (USA, 1891) [1] was one of the first who proposed solid-phase friction welding of pipes and rods, and then Khrenov and Sakhatsky (PWI, 1953) carried out «cold» friction welding [2]. Chudikov (1957) [3] can also be referred to the first developers of friction welding and surfacing. Method of rotation friction welding of metals developed by Kabanov and Averin (1960) [4] is one of the solid-phase friction welding methods, which has received wide distribution. However, this approach can not be used for butt and lap welding of the flat sheet structures as well as surfacing of other metals and alloys.
Application of the principle of solid-phase friction butt and lap welding of flat or curved sheet parts was proposed in 1991 in patent of Thomas et al. [5]. They proposed the method of welding of parts using active non-consumable tool. This technology, which authors called friction stir welding (FSW), provides for very simple method of tool and workpiece interaction.

Designs and materials of FSW tools. The method of dissimilar parts joining by FSW, proposed by Thomas and his colleagues, can be referred to the most significant technological achievements for the last thirty years. It provided for the possibility to join the parts from the materials which earlier couldn't be welded at all by traditional arc welding or was difficult-to-weld, i.e. different aluminum, magnesium and titanium alloys. Application of new technology expanded the possibilities of reconstruction and repair of complex equipment by means of deposition of new layer of metal over part surfaces.

However, regardless the success of FSW, there are a lot of problems which should be solved for expansion of industrial application of this technology. Among them the main problem is providing the process with safe, reliable and wear-resistant tool. In the process of welding the tool is simultaneously subjected to the effect of torque moment, alternating-sign cyclic bending forces as well as effect of high temperatures. Absence of reliable answers to these questions in the world scientific resources makes difficult application of new advanced technology, i.e. FSW, in 
a broad-scale. Figure 1 shows a schematic diagram of operation of the tool, which is used in FSW of different metals [5].

For a long time the E.O. Paton Electric Welding Institute has been carrying out the experimental works in «cold welding» [6], and in course of several years V.N. Bakul Institute for Superhard Materials has been performing the works on development and application of the tools for FSW of different metals and alloys [7-10]. Analysis of available sources on manufacture of such type tools gives an idea of the materials which should be used at that [11-14].

These materials should keep high hardness and strength at high temperatures. At that their properties should significantly exceed mechanical characteristics of the materials being welded or surfaced. Besides, the tool, in particular, its working part, should have high wear and heat resistance. These properties are, first of all, determined by significant temperatures and forces on the tool, which appear in welding or surfacing.

The working tips of FSW tools are made in form of cylinders with rounded edges, cones or cylinders. On the surfaces of the latter a complex-shape groove with shiftable step is cut, which should promote better metal movement within the weld. As a rule the groove has a direction opposite to tool rotary motion. Probably, in order to provide better weld formation and reduce forces on the tool, the latter is set not vertically to surface plane, but at small angle $2-5^{\circ}$ to the side opposite to advance direction.

The complex shape of pins are necessary to provide the best metal stirring as possible in order to increase welding process efficiency. The results of multiple investigations showed the relationship between heat, which is generated depending on process kinematic parameters, and weld static strength [10]. Also a change was observed in the microstructure of $\mathrm{HAZ}$ as well as stirring zone in comparison with base material.

Analysis of data, received on tools for FS surfacing and welding, for the first stage allowed making a conclusion on producing the tool samples from high-strength tool steel. These samples were manufactured from highspeed steel R18, quenched at $1270{ }^{\circ} \mathrm{C}$. After quenching the tool was subjected to 1 hour tempering at 550-570 ${ }^{\circ} \mathrm{C}$ for transformation of residual austenite into martensite and dispersion quenching (secondary hardening). Steel hardness of the part reached HRC 65 as a result of heat treatment. The tools with higher hardness can be produced by application of powder steels, developed for replacement of R18 and R9 steels, namely ROM2F 3-MP, M6F 1-MP and M6F 3-MP.

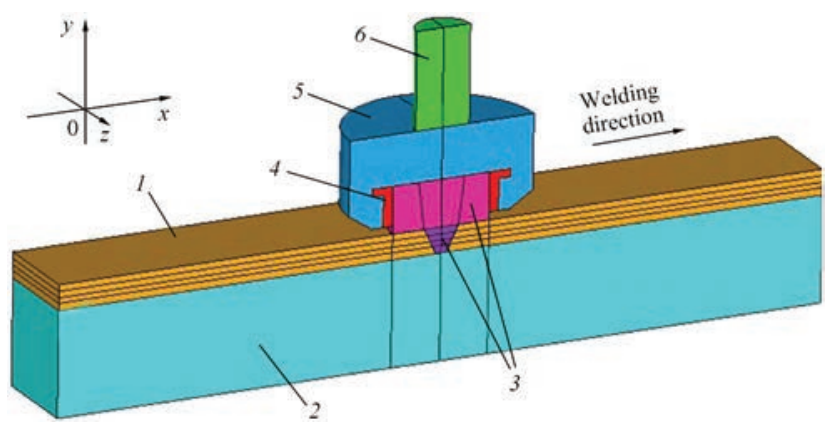

Figure 1. Schematic of FSW process: 1, 2 - part being welded; 3 - tool with shoulder; 4 - hard alloy casing; 5 - steel holder; 6 - drive steel shaft

Application of steel in tool manufacture allows having the pin of complex shape, which is not always possible in use of ultra-hard materials. Besides, price of the tool will be significantly less, that makes its application economically effective in series of cases.

There are steel grades, physical-chemical properties of which can be used for the FSW tool. At that, tungsten-alloyed tool steels, namely R18 and R9M4 $\mathrm{K} 8$, such called highs speed steels [7,8], have the largest strength. However, their heat resistance is in the range of $600-650^{\circ} \mathrm{C}$, that states these steels application only for welding of parts from fusible alloys. Austenite class steels 20Kh23N18 and 12Kh25N$16 \mathrm{G} 7 \mathrm{AR}$ have somewhat lower strength indices, but their heat resistance is significantly larger and reaches $1000{ }^{\circ} \mathrm{C}$. Analysis of known properties of alloys based on chromium, nickel and cobalt indicates the necessity in the tools from heat- and wear-resistant materials, design of which was developed in scope of «Resurs» program (Figure 2) [7, 8] for FSW of these alloys.

Thus, the tools for FSW of relatively fusible aluminum and magnesium alloys, shown in general in Figure 2, a, were developed and manufactured. At the same time, the attempts to use steel tool for surfacing of nickel or cobalt on copper substrate didn't give positive results due to relatively high temperature in FSW zone. Therefore, the tools from hard alloy VK8 (Figure 2,b) were manufactured for FS welding and surfacing of copper and its alloys, and the tools from polycrystal cubic boron nitride (CBN)-based ultra-hard material (Figure 2,c) (Table 1) [7] were used for FSW of steels, nickel, cobalt and other refractory metals and alloys.

However, even application of powder metallurgy does not always provide for radical increase of strength of steel tool for FSW and dramatically increases its costs and terms of production. Thus, a decision was made on application of the tools from hard alloy or polycrystal ultra-hard materials (PUHM) (Table 1) [7, 8] for welding of materials with higher strength and 


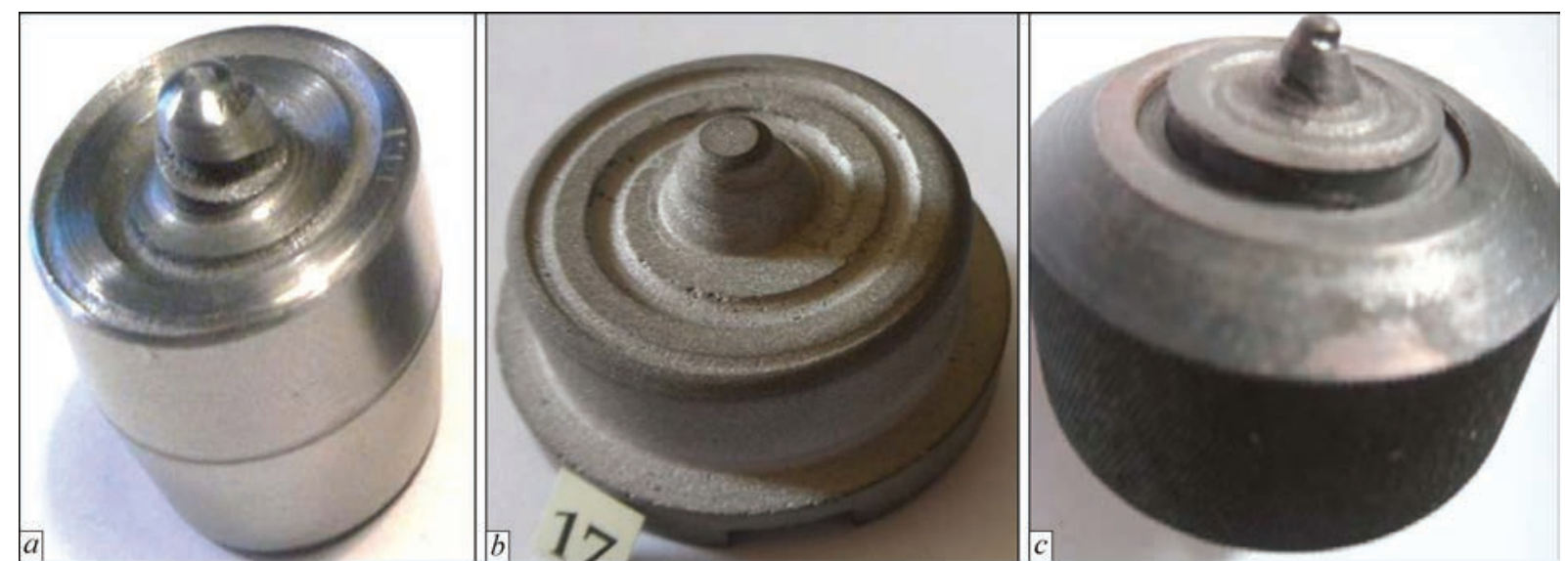

Figure 2. View of tools for welding, surfacing and modification of metal by friction stir process [7, 8]; $a$ - from steel R18 for FSW and modification of structure of aluminum and magnesium alloys; $b$ - from hard alloy VK8 for surfacing of copper; $c$ - from CBN for surfacing of nickel and cobalt

larger melting temperature, such as copper and nickel. Such high physical-mechanical properities, respectively, gives rise to complex and laborious machining of tools from CBN.

The investigations show that very thin and homogeneous grain structure $[9,10]$ is formed during FSW in the zone of tool proceeding. Also, it should be noted that hardness of material being processed to significant extent depends on rotation and forward speeds of the tool and is widely varied in processing area. They determine distribution of material deformation rates in the processed zone, correlating with deformation rate distribution and average size of grain microstructure, bound by Zener-Hollomon parameter.

Grant and Weil [15] investigated the process of solid-phase FSW. They showed that tool immersing the subsurface layer of metal, as a result of friction work and plastic deformation, provides for metal heating to the temperature sufficient for reduction of yield point and hardness to visco-plastic state. At that, the authors have proposed to divide FS-welded joint cross-section on conventional zones, namely finegrain «core» of weld stirred metal (SM) consisting of re-crystallization zone with changed microstructure, thermomechanical-affected zone (TMAZ), HAZ and base metal.

This work pays main attention to the peculiarities of structure in weld SM zone and TMAZ, formed in stir friction.

Research of heat generation in zone of FS-welded processing of magnesium alloys. Investigation of the process of heat generation at interaction of the tool with processed surface layer of metal is carried out by setting the compound parameters of tool loading and measurement of distribution of tool heating temperature. However, structure of metal and parameters of this zone will depend on shape and size of the tool, physical-mechanical characteristics of processed material and kinematic parameters of tool movement. Therefore, one of the priority tasks in development of FSW tool is to determine the temperature distribution in different points of zone of its interaction and, thus, study the thermal-physical conditions of operation, and, based on that, create more well-grounded boundary conditions for solution of the problem on thermo-stressed state of FSW tool depending on kinematic parameters of its movement [10].

It is a well-known fact that a heat source of large intensity is formed in the FS process due to friction between tool rotating surface and metal of the part as well as deformation work of this metal. Therefore, the process of heat generation in stir zone during FSW or modification of structure of surface layers of metals and alloys depending on kinematics and force parameters of tool interaction with metal of the part [16] was studied for determination of main factors of effect of stir or welding process on change of metal structure in this zone.

Magnesium alloy ML10, which is widely used in aircraft and space technologies, was taken as an object for investigation of effect of FS process on change of metal structure state. Let's consider some reference properties of this alloy related with heat-resistant cast magnesium alloys $[17,18]$. ML10 alloy is

Table 1. Physical-mechanical properties of some materials used for FSW tool manufacture [7, 8]

\begin{tabular}{|c|c|c|c|c|c|c|}
\hline Material & HRC & $H V, \mathrm{GPa}$ & $\sigma_{\text {bend }}, \Gamma \Pi \mathrm{a}$ & $\sigma_{\text {comp }}, \Gamma \Pi \mathrm{Ha}$ & $\mathrm{Heat} \mathrm{resistance,} \mathrm{K}$ & $\mathrm{CTE} \alpha \cdot 10^{-6} \mathrm{~K}^{-1}$ \\
\hline High-speed steel & $62-67$ & - & $2-6$ & $2.5-4.0$ & $900-1000$ \\
\hline Hard alloy & $88-89$ & $13-14$ & $0.75-2.60$ & $3.5-5.9$ & $1100-1300$ \\
\hline PUHM-CBN & - & $30-40$ & $0.4-1.5$ & $2.0-6.5$ & $3.0-7.5$ \\
\hline
\end{tabular}



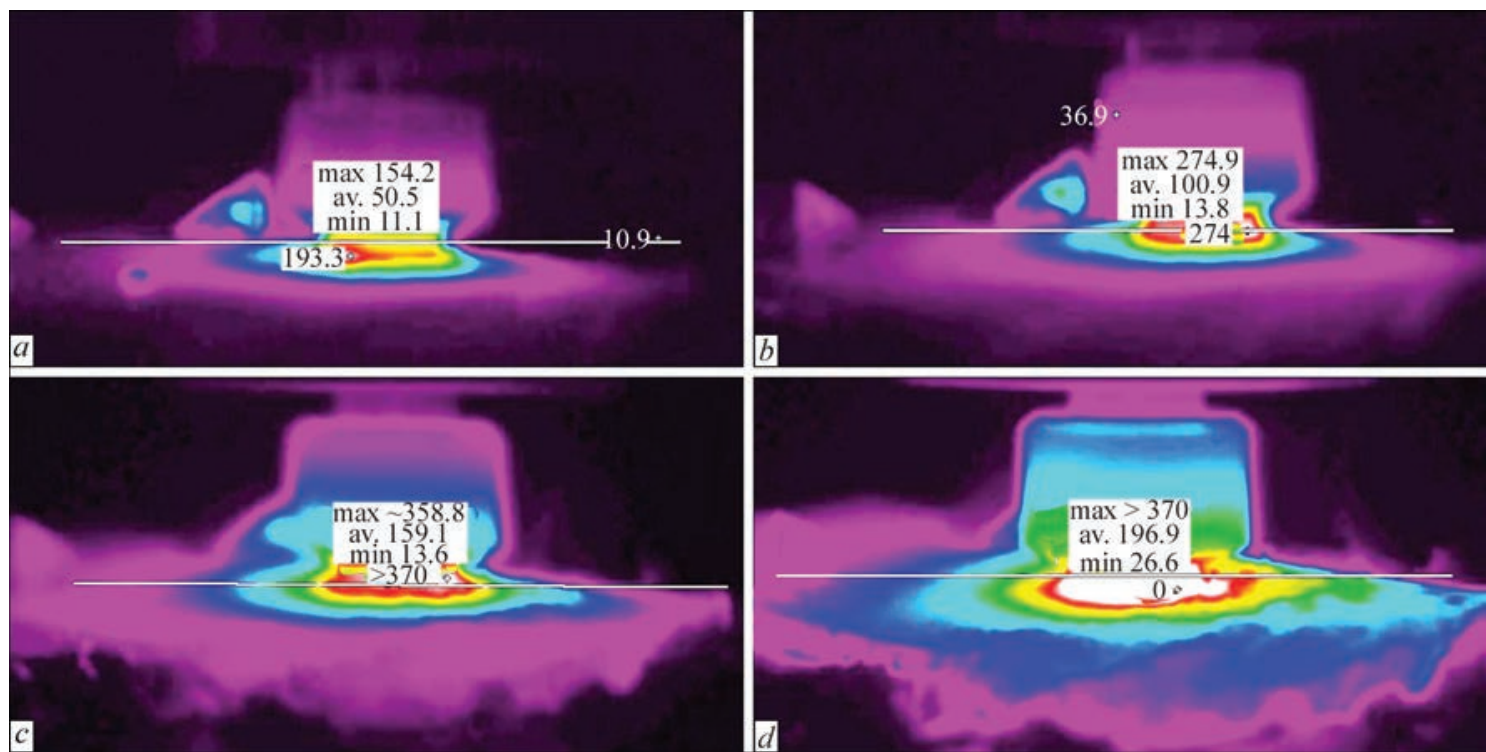

Figure 3. Change of Fluker-ir25-measured temperature distribution on surface of ML10 sample at tool movement over sample of 5 $(a), 10(b), 15(c)$ and $20(d) \mathrm{s}$

referred to $\mathrm{Mg}-\mathrm{Nd}-\mathrm{Zr}$ system. The structure of this alloy represent itself a solid solution of $\mathrm{Nd}, \mathrm{Zr}$ and $\mathrm{Zn}$ in $\mathrm{Mg}$ and their eutectics along the grain boundaries, which includes $\mathrm{Mg} 9 \mathrm{Nd}$ compound. The average size of grains of initial alloy ML10 reaches $75-100 \mu \mathrm{m}$. The mechanical properties of alloy at room temperature are sufficiently high, but the main peculiarity of its properties is the fact that they are kept at elevated (up to $250{ }^{\circ} \mathrm{C}$ ) temperatures.

Processing the surface layers of samples of alloy ML10 was carried out using steel tool to $6 \mathrm{~mm}$ depth with six modes of tool rotation: $v_{\mathrm{w}}=20-40 \mathrm{~mm} / \mathrm{min}$ and tool rotation rate $\omega=600-800 \mathrm{rpm}$ [9]. Temperature measurements and determination of temperature field distribution in zone of ML10 alloy modification were registered with the help of infra-red imager Fluke-ir25 at different moments of tool movement over the sample (with $5 \mathrm{~s}$ increment) (Figure 3). Table 2 shows the average values of temperature in zone of FS processing on surface of ML10 samples at different kinematic parameters of tool movement in their surface layer. It is noted that the maximum temperature of ML10 alloy heating in the zone of contact interaction of the tool with processed layer of the sample reached $380{ }^{\circ} \mathrm{C}$.

Figure 4 shows in-time variation of temperature distribution in the section across the width of tool in-

Table 2. Change of maximum temperature in zone of processing of ML10 samples at different kinematic parameters of tool movement in sample surface layer

\begin{tabular}{|c|c|c|}
\hline \multirow{2}{*}{$v_{\mathrm{w}}, \mathrm{mm} / \mathrm{min}$} & \multicolumn{2}{|c|}{$T_{\max },{ }^{\circ} \mathrm{C}$, at $\omega, \mathrm{rpm}$} \\
\cline { 2 - 3 } & 630 & 800 \\
\hline 20 & 360 & 350 \\
\hline 31.5 & 350 & 360 \\
\hline 40 & 340 & 380 \\
\hline
\end{tabular}

teraction zone. At that, it should be noted that temperature in zone of tool effect shall reach $(0.4-0.6)$ $T_{\mathrm{m}}$ for realization of FSW (FS) process. The results of carried measurements allowed determining not only the average temperature values on the surface of contact zone, but also time which is spent before the beginning of tool immersion in the metal up to reaching a thermal balance of heat flows which are formed directly in the processing zone, and heat flow which is emitted from the surface of sample and tool. Thus, thermal balance in the processing zone is stabilized in 15-20 s (see Figure 4) $[9,16]$.

Obtained result can be considered from technological point of view, which lies in the necessity of receiving similar conditions of tool operation with part metal. Therefore, it should be considered that before tool entering in the zone of part processing, the metal reaches necessary temperature only in 15 s, i.e. the process of part processing shall be done only using artificial support.

Modifying the structure of surface layer of magnesium alloys. Modifying the alloy structure is

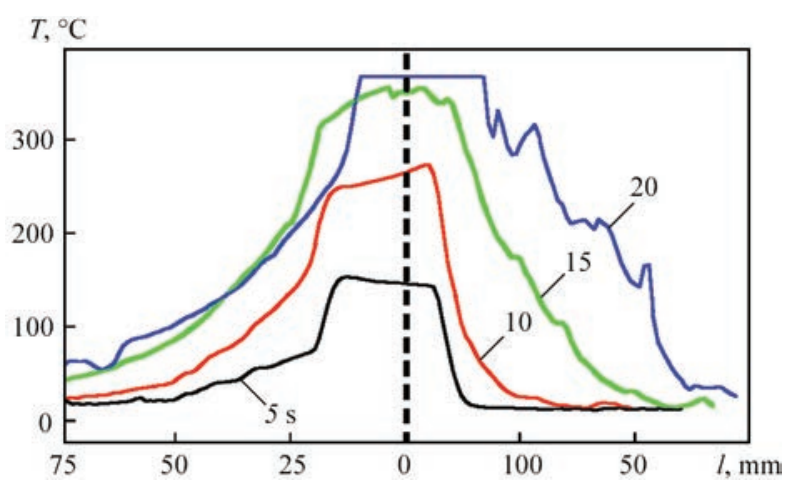

Figure 4. In-time change of temperature distribution in contact zone of tool with surface layer of ML10 sample from the beginning of its horizontal movement 


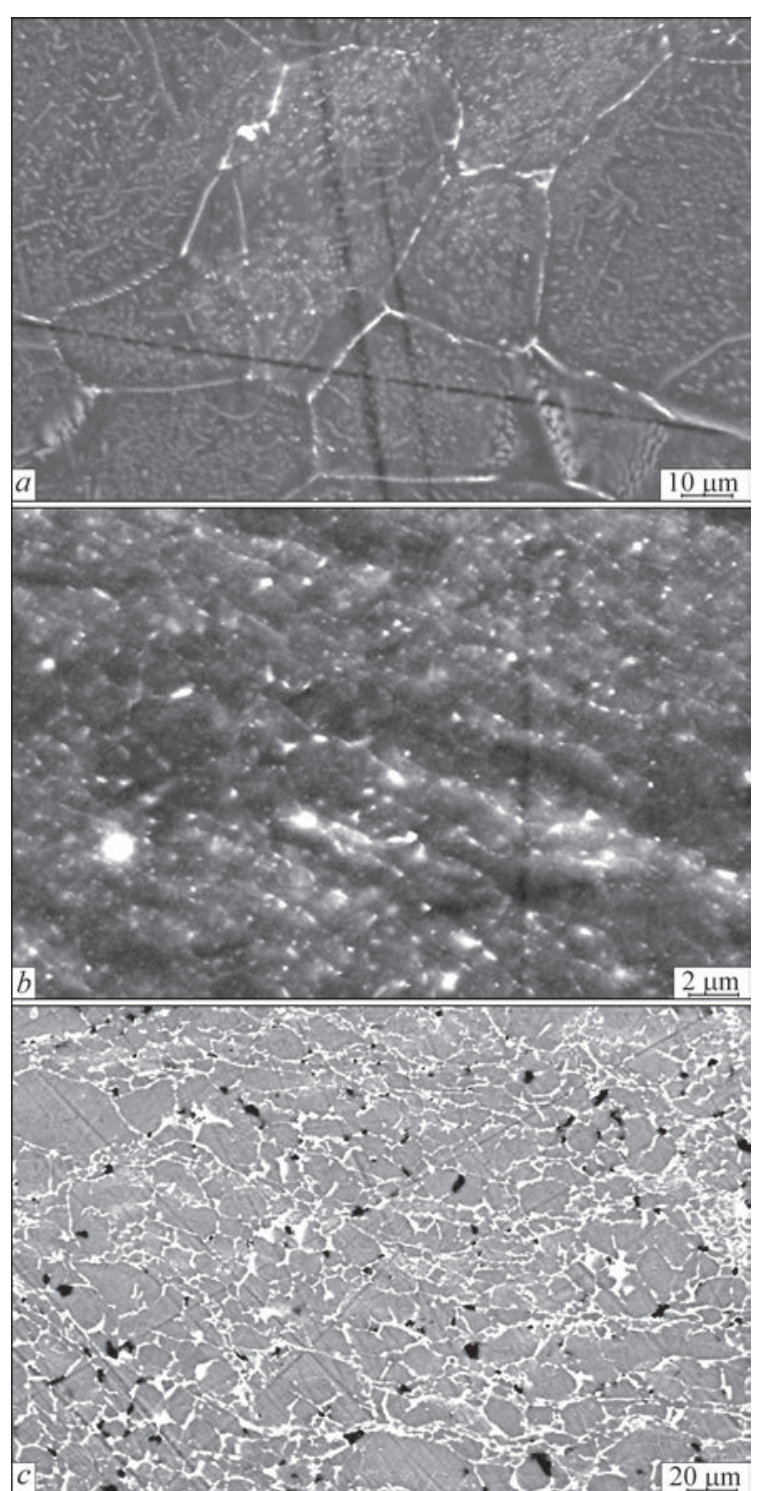

Figure 5. Size of grains of ML10 alloy in FS processing zones: $a$ - base metal $\left(d_{\mathrm{av}}=75.8 \mu \mathrm{m}\right) ; b-\mathrm{SM}$ zone $(1.2-4.5 \mu \mathrm{m}) ; c-$ intermediate TMAZ zone between SM and base metal $(7.8 \mu \mathrm{m})$

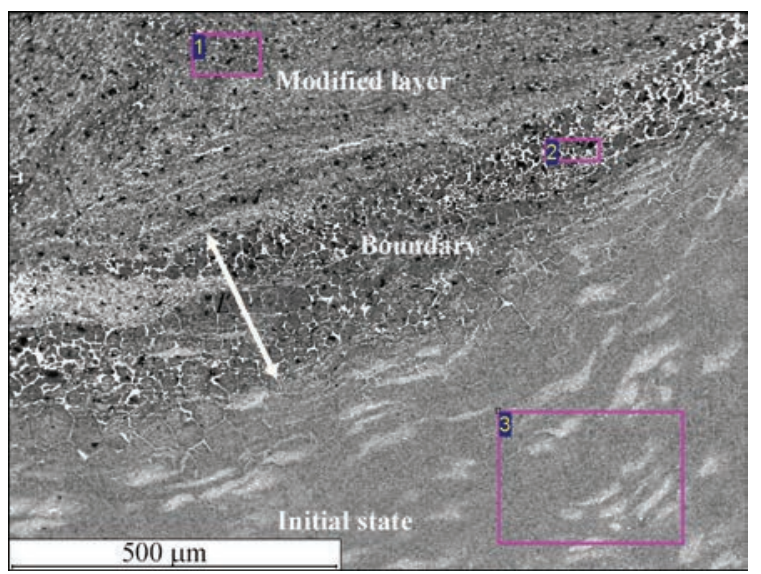

Figure 6. Microstructure of modified surface layer of ML10 sample at FS processing mode 1 (here and in Figures 7-11 mode parameters see in Table 3)

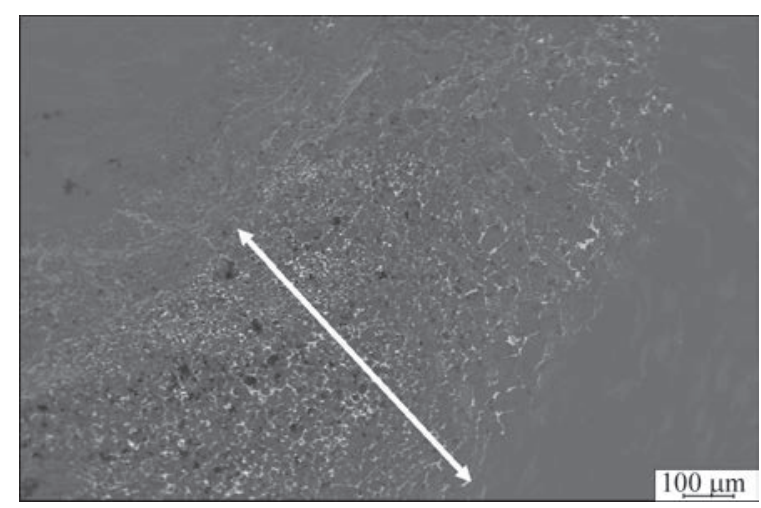

Figure 7. Microstructure of modified surface layer of ML10 sample at FS processing mode 2

the process of change of its structure similar to that which takes place in metal structuring in hot rolling or forging, i.e. structuring and refining of grain structure under the effect of intensive plastic deformations. Researches on FSP of the surface layers of parts from magnesium alloys are directed on determination of the effect of kinematic and force parameters on change of structure and properties.

Modification of the structure of surface layers of alloy ML10 was carried out with steel tool to $6 \mathrm{~mm}$ depth. As it was mentioned above, the tool in FSW forms SM zone and TMAZ, which later on determines the strength of joining of stirred metal with base metal, and HAZ (Figure 5). Structures of the base ML10 metal and different SM zones and TMAZ were analyzed using standard stereology methods. It made a basis for determination of the values of average alloy grain size in these zones in comparison with the value of alloy grains in the initial condition $\left(d_{\mathrm{av}}=75.8 \mu \mathrm{m}\right)$.

Thus, the distribution of average values of grain size in the zones of technological ML10 alloy processing was determined as a result of carried investigation, namely in ML10 base metal $d_{\mathrm{av}}=75.8$, in TMAZ - 7.8, in SM zone - 1.2-4.5 $\mu \mathrm{m}$.

Effect of kinematic parameters of tool movement on formation of intermediate TMAZ in FSW of ML10 alloy. Let's consider the effect of kinematic parameters of tool movement at different processing modes on formation of structure and thickness $L$ of the intermediate TMAZ in FSW of magnesium alloy (Table 3; Figures 6-11). As it was mentioned above,

Table 3. Effect of FSW parameters on thickness of transition zone of TMAZ with base ML10 metal mating

\begin{tabular}{|c|c|c|c|}
\hline $\begin{array}{c}\text { Mode } \\
\text { number }\end{array}$ & $\begin{array}{c}v_{\mathrm{w}} \\
\mathrm{mm} / \mathrm{min}\end{array}$ & $\omega, \mathrm{rpm}$ & $L, \mu \mathrm{m}$ \\
\hline 1 & 20 & 630 & 250 \\
\hline 2 & 31.5 & 630 & 800 \\
\hline 3 & 40 & 630 & 1200 \\
\hline 4 & 20 & 800 & 1100 \\
\hline 5 & 31.5 & 800 & 800 \\
\hline 6 & 40 & 800 & 300 \\
\hline
\end{tabular}




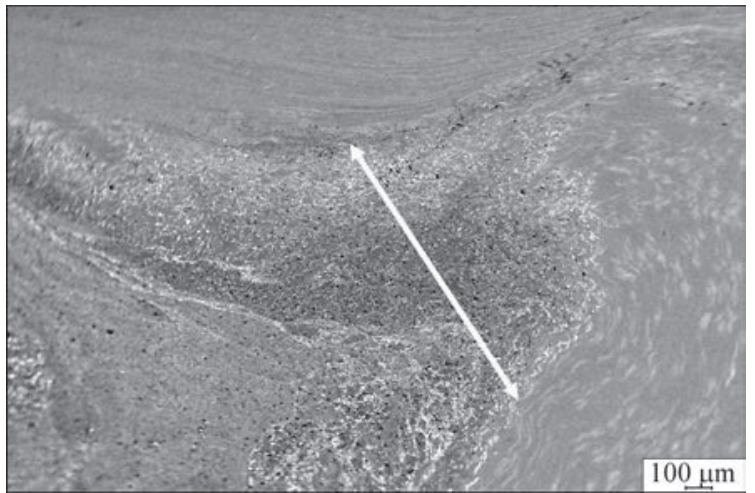

Figure 8. Structure of modified surface layer of ML10 sample at FS processing mode 3

the structure of SM zone and TMAZ was formed at set kinematic parameters and depth of tool immersion in the surface layer to $6 \mathrm{~mm}$.

Analysis of images of metal structure in FSW zones at different kinematic modes of surface layer modification was performed. It allowed making a conclusion that FSW at $v_{\mathrm{w}}=40 \mathrm{~mm} / \mathrm{min}$ and $\omega=$ $=630 \mathrm{rpm}$ approaches to the optimum for ML10 alloy because at that the thickness of TMAZ achieves the maximum size $L=1200 \mu \mathrm{m}$. Meeting this particular condition at the boundary of TMAZ and base metal eliminates formation of lamination and cracks, that provides for maximum strength of the joint.

The following conclusions can be made based on carried analysis of structure of magnesium alloy ML10 after FSP.

Fundamental changes of the structure are observed in FS zone and HAZ in contrast to base metal. This is a consequence of refinement of the initial metal grains (to $1.2-4.5 \mu \mathrm{m}$ ), that is $16-63$ times less than the size of grains in the base metal $(75.8 \mu \mathrm{m})$. This effect is characteristic for all FS-welded joints independent on technological parameters of welding.

Weld metal structure in the cross section is virtually uniform, except for the zone of its mating with the base metal and subsurface area of weld face, which was formed at contact with rotating tool. Formation

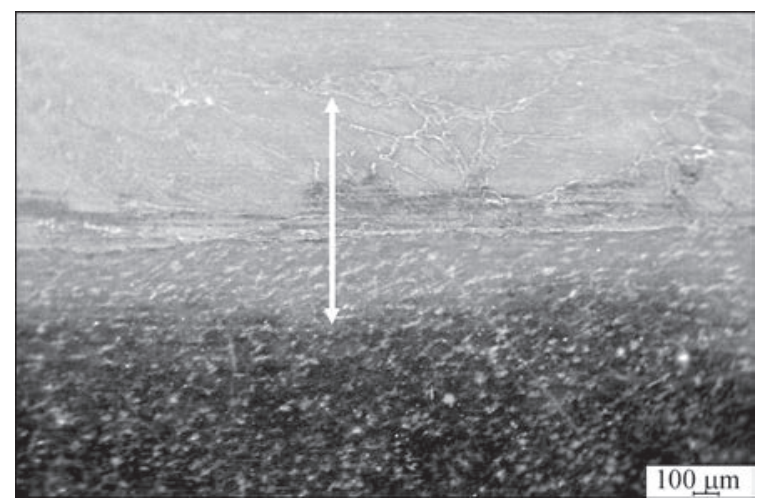

Figure 9. Structure of modified surface layer of ML10 sample at FS processing mode 4

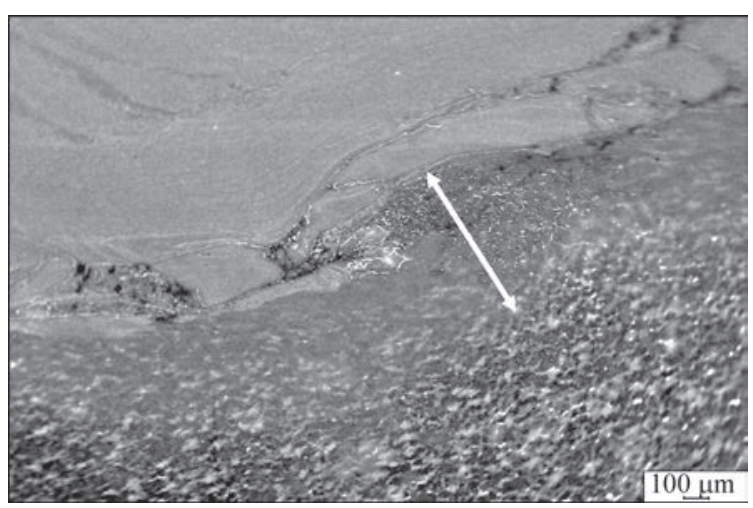

Figure 10. Structure of modified surface layer of ML10 sample at FS processing mode 5

of fundamentally other structure, namely fine and close to equilibrium one, takes place due to base metal grain refining as a result of plastic deformation in FSW process. It allows obtaining higher properties of weld metal strength and ductility. TMAZ metal structure of near-weld zone in joint can be compared with the initial one, but in contrast to texture of base metal it virtually has 10 times difference on grain size $\left(d_{\mathrm{av}}=\right.$ $=7.8 \mu \mathrm{m})$, oriention as well as shape of grains.

The zone of weld to base metal mating is the zone which represent itself TMAZ of 250-1200 $\mu \mathrm{m}$ width with adjacent to it metal volumes from the side of weld and base metal. TMAZ metal as well as weld metal is the zone of maximum metal heating, which is subjected to intensive mechanical impact of rotating welding tool. The width of TMAZ in ML10 alloy welded joint has direct dependence on heat effect in welding. TMAZ metal structure is a transfer one from fine-grain (in weld SM) to re-solidified, which partially preserves the base metal texture. Fine equiaxed disordered grains are observed from the side of base metal along the boundaries of coarse grain. Such change of structure is a consequence of effect on nearweld zone metal of significant plastic deformations which take place in process of welded joint formation as well as of processes of re-crystallization under conditions of heating in FSW.

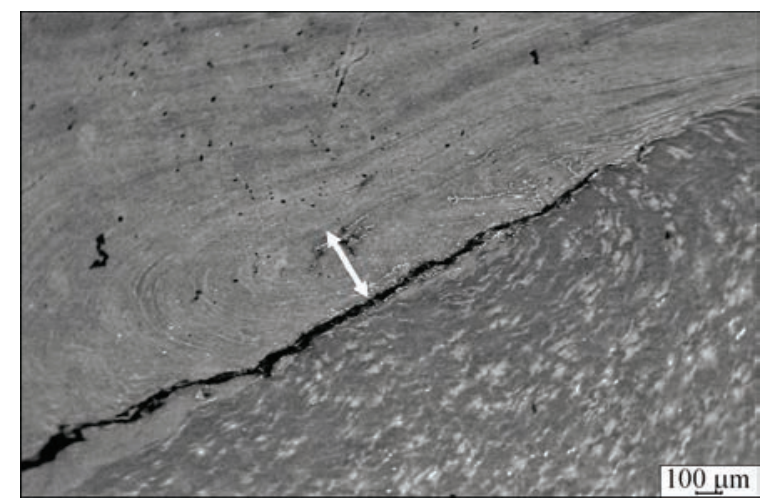

Figure 11. Structure of modified surface layer of ML10 sample at FS processing mode 6 
The average size of grains in TMAZ makes $7.85 \mu \mathrm{m}$ that is 10 times less the size of base metal grains. The maximum thickness of TMAZ with re-solidified structure reaches $1200 \mu \mathrm{m}$, at that the maximum values of temperature of metal heating on weld surface for investigated FSW modes $\left(v_{\mathrm{w}}=40 \mathrm{~mm} / \mathrm{min}\right.$ and $\omega=630 \mathrm{rpm})$ do not exceed $340-350^{\circ} \mathrm{C}$. The results of metallographic investigations showed that TMAZ near-weld metal can be the weakest chain between base and weld metal. Thus, welding is reasonable to be performed using modes with limited heat generation for reduction of softening thermal effect of FSW.

Fracture and disorienting of crystallites of initial metal, appearing in formation of fine-grain structure (grain size $1.2-4.5 \mu \mathrm{m}$ ), that is $16-63$ times less than the initial grain size $(75.8 \mu \mathrm{m})$, was determined in FS zone of magnesium and aluminum alloys using reflection electron diffraction method on SEM with energy-dispersive analyzer.

1. Bevington, J.H. Spinning tubes. Pat. 444721 US. Pat. 13.01.1891.

2. Khrenov, K.K., Sakhatsky, G.P. Method of cold butt welding of metal products. USSR author's cert. 97024. Fill. 20.07.53.

3. Chudikov, A.I. Method of butt welding. USSR author's cert. 106270. Int. Cl. B23k 20/12. Publ. 1957.

4. Kabanov, N.N., Averin, I.V. Method of friction butt welding of dissimilar metals. USSR author's cert. 126732. Fill. 03.06.59. Publ. 01.01.60.

5. Thomas, W.M., Nicholas, E.D., Needham, J.C. et al. Friction stir butt welding. Pat. 9125978.8 GB; 5460317 USA. $\mathrm{PCT} / 92 / 02203$.

6. Poklyatsky, A.G., Ishchenko, A.Ya., Yavorskaya, M.R. (2007) Strength of joints on sheet aluminium alloys produced by friction stir welding. The Paton Welding J., 9, 42-45.

7. Zelenin, V.I., Poleshchuk, M.A., Zelenin, E.V. et al. (2010) Repair of plates of continuous casting copper molds by fric- tion stir surfacing. In: Rock cutting and metal-working tool technique and technology of its manufacturing and application, Issue 13, 476-479.

8. (2013) Development of design and manufacturing technology of tool for friction stir welding of alloys based on $\mathrm{Cr}, \mathrm{Ni}$, Co. Manufacturing of tool prototypes and realization of laboratory experiments on nature of their wear and fracture during operation: Report of works on agreement P7.5.2. Kyiv: ISM.

9. (2014) Development of friction stir welding tools from superhard materials designed for manufacturing and restoration of life of aluminium and magnesium alloys: Report of works on agreement P8.6.1. Kyiv: ISM.

10. Majstrenko, A.L., Nesterenkov, V.M., Dutka, V.A. et al. (2015) Modeling of heat processes for improvement of structure of metals and alloys by friction stir method. The Paton Welding J., 1, 2-10.

11. Rai, R., De, A., Bhadeshia, H.K.D.H. (2011) Review: Friction stir welding tools. Sci. and Tech. of Welding and Joining, Vol. 16, 325-342.

12. Mironov, S.Yu. (2014) Formation of grain structure in friction stir welding. Fizich. Mezomekhanika, Issue 17, 103-113.

13. Lee, J.A., Carter, R.W., Ding, J. (1999) Friction stir welding for aluminium metal matrix composites (MMC's): MSFC Center Director's Discret Fund. Final Report TM-1999209876. NASA.

14. Shtrickman, M.M. (2007) State and development of friction welding process of linear joints (Review). Svarochn. Proizvodstvo, 10, 25-32.

15. Grant, G., Weil, S. (2011) Joining technologies for coal power applications. In: Advanced Res. Materials Program: Ann. Rev. Meet. Proc. (Portland, Apr. 26-28, 2011).

16. Nesterenkov, V.M., Majstrenko, A.L., Lukash, V.A. et al. (2013) Possibilities of modification of light alloys structure by stir friction. In: Proc. of Int. Sci.-Techn. Conf. on New and Unconventional Technologies in Resource and Energy Savings (22-24 May 2013, Odessa, Ukraine), 117-120.

17. Kolobnev, I.F., Krymov, V.V., Melnikov, A.V. (1974) Reference book of founder. Nonferrous castings. $2^{\text {nd }}$ ed. Moscow: Mashinostroenie.

18. Portnoj, K.I., Lebedev, A.A. (1952) Magnesium alloys: Refer. Book. Moscow: Metallurgizdat. 